\title{
Russian Technograds: The Technological Profiles of the Cities
}

\author{
Ekaterina Streltsova \\ Senior Research Fellow, Institute for Statistical Studies and Economics of Knowledge (ISSEK), kstreltsova@hse.ru
}

\section{Gleb Kuzmin}

Leading Expert, Institute for Statistical Studies and Economics of Knowledge (ISSEK), gkuzmin@hse.ru

National Research University Higher School of Economics, 20 Myasnitskaya Str., Moscow, 101000, Russian Federation

\begin{abstract}
$\mathrm{T}$ The paper discusses the technological specialization and patent portfolios of the Russian 'technograds' the cities which are the key actors in contributing to the development of new technologies in the country. A patent analysis used for the study allowed us to identify technological domains where these cities have a significant competitive advantage and high potential for further growth. According to the research-intensity of the domains prevailing in their technological specialization, the technograds might be divided into three categories: oriented towards mostly high technologies (Moscow, St Petersburg, Tomsk), low

technologies (Krasnodar, Perm), and those with mixed specialization including both high and low tech (Voronezh, Ufa, Kazan, Novosibirsk, Ekaterinburg, and Samara).

To achieve the aim of the research, a new methodological approach was elaborated upon to analyze patent data for individual cities and other smaller geographical units. As a result, the paper might be of interest not only for practitioners and decision makers on the regional and municipal levels, but also for researchers in the fields of regional economics, economic geography, and economics of science, technology, and innovation.
\end{abstract}

Keywords: technological specialization; technological development; technological resilience; cities; patent analysis; Russia
Citation: Streltsova E., Kuzmin G. (2019) The Russian Technograds: The Technological Profiles of the Cities. Foresight and STI Governance, vol. 13, no 3, pp. 41-49. DOI: 10.17323/2500-2597.2019.3.41.49 
$\mathrm{I}$ $\mathrm{n}$ the research literature, large cities are traditionally believed to be the main "growth points" of national economies, as industry, science, and technology development centers [Boschma et al., 2014; Jacobs, 1969; Glaeser et al., 1992; O'hUallachain, 1999]. Facilitating the emergence of agglomerations serves as an efficient tool for promoting this growth [Andersson et al., 2005] by concentrating resources and creating conditions to encourage the free exchange of ideas between individuals, organizations, and industries which ultimately results in higher innovation activity [Balland, 2015a; Carlino, Kerr, 2014; Jacobs, 1969; 1984; Jaffe et al., 1993]. Due to their important role, large cities inevitably command the attention of researchers specializing in a wide range of disciplines, including spatial and regional economics, economic geography, urbanistics, science, technology, and innovation economics, and so on. Apart from purely theoretical issues, these disciplines also deal with applied objectives, among other things, they analyze modern agglomerations' technological specialization and potential.

Major Russian cities certainly make a large contribution to the country's technological development. They are where most new technologies are developed, as evidenced by patent statistics. In 2017 about a third of all patent applications for inventions filed in Russia were filed in two cities, Moscow $(5,500)$ and St. Petersburg $(1,600)$ [Rospatent, 2018]. Meanwhile, the capital (and other) cities' technological specializations (i.e. priority areas for the development of new technologies that focus on the domestic or global market) remains poorly researched in the Russian literature. A possible reason is the lack or insufficient availability of the required data: relevant statistics are aggregated only at the regional level, while other data sources (such as patent databases) frequently have only national-level figures (by inventors' and applicants' country).

Our paper aims to fill a gap by presenting the results of analyzing the technological specialization of Russian "technocities", or "technograds", which are the national leaders in new technology development. This is an important and very practical research objective as it would help not only identify the cities' current thematic priorities and potential but also predict future technology development paths and assess their vulnerability in the event of a crisis. The importance of this work is confirmed by various studies on assessing the impact of specialization upon cities' technological diversification and the growth of their innovative activity.

\section{Cities' Technological Specializations and Sustainability}

Technological specialization is analyzed at different levels: for particular organization types [Dachs et al., 2007; Pattel, Pavitt, 1991], industries [Ha et al., 2015], regions, and countries [Archibugi, Pianta, 1992; Ejermo, 2005; Pianta, Meliciani, 1996]. However, at the level of cities, such studies are conducted much less often. For example, one of the best-known works in this field [Cortright, Mayer, 2001] presents an evaluation of the specializations of 14 US cities that are considered high technology development centers. Having analyzed the employment, patenting activity, and venture capital flows, the authors discovered that despite the cities' common focus on promoting high-tech industries, each of them has a particular and very narrow specialization. For example, developers in Atlanta specialize in databases, in Boston - computer technologies, medical equipment, and software, in Denver - data storage technologies and equipment, telecommunication software, and other areas. The dynamics of US cities' specialization and the different paths of their technological development are also discussed in [Rigby, 2015; Kogler et al., 2013]. A few studies of this kind were carried out in other countries too, in particular in Germany [Vlckova, et al., 2018] and China [Xia, Hu, 2014].

An attempt at international comparison was made in [Kogler et al., 2018]. The authors compared the patent portfolios of 20 large cities in five countries: China, France, Israel, the Netherlands, and the US. The study revealed significant differences in the agglomerations' technological specializations, including in the same country. According to the authors, their results have significant practical value since they clearly demonstrated that a "one-fits-all" approach cannot be applied to manage cities' technological and innovative development.

Such rapt attention to technological specialization at all levels is due to the latter's potentially high economic importance. Understanding the limits of specialization allows one to identify the competitive advantages of organizations, regions, or countries, along with determining their position in regional, national, or global technology markets [Giannitsis, Kager, 2009], and (provided wise and efficient management decisions are made) turn the existing technology profile into a source of advantages. This analysis becomes particularly relevant during economic crises or cost optimization periods, when investment priorities need to be set. Assessing specialization not only helps one to better understand the available competencies but forecast 
future technological development, since the latter is path dependent while its scope is limited by the range of technologies that are being successfully developed in the country, region, or city at present [Cantwell, Vertova, 2004; Strumsky et al., 2012]. [Boschma et al., 2014] come to similar conclusions, having analyzed the patenting activity in 366 US cities in 1981-2010. Their study revealed that new technologies that fit into the specialization areas in the city's portfolio are more likely to emerge and successfully develop. And vice versa, technologies completely unrelated to these specialization areas (i.e., those with a low relatedness level $)^{1}$ face the risk of gradually fading and disappearing. Rigby [Rigby, 2015] also analyzed the dynamics of various technologies' development in major US agglomerations and their relation to the cities' current technological specialization. He concluded that in most cases the available competencies tend to fall within a limited range of related technologies. Further, these competencies determine future knowledge creation paths. "Core" cities tend to be highly inertial: radical changes in their technological specialization occur rarely, and if they do, the process is likely to be quite slow.

Understanding regions' and cities' specialization can also be useful for predicting the risks of "technological crises", that is, long periods of decline in inventive and, as a consequence, patenting activity caused by various external shocks or internal factors. A number of studies in the field of regional and urban technological resilience (e.g., [Balland, et al., 2015b; Boschma, 2015]) showed that cities where technological "despecialization" is taking place, those that develop a whole range of technologies unrelated to each other, are less likely to experience technological crises, tend to recover from them faster, and on the whole perform "technological updates" more efficiently. On the contrary, cities with a narrow specialization tend to experience more pronounced periods of technological decline (with a deeper drop in patenting activity level), which happen more often and last longer.

Thus, the results of previous studies indicate that assessing Russian cities' technological portfolios and identifying priority technology areas for them would be quite useful. This will help, firstly, to determine the "core" competencies of the territorial units that currently drive the country's technological development and more accurately describe the Russian technological landscape. Secondly, predicting future technology development paths in Russian urban agglomerations will become possible, along with assessing their potential for diversifying current technology portfolios. Finally, analyzing the specialization structure will help predict the onset of technological crises in Russian technocities and the latter's recovery potential. The novelty of the proposed approach is confirmed by the lack of such studies based on domestic material.

\section{The Empirical Basis and Methodology of the Study}

Assessments of technological specialization are traditionally based on analyzing patenting activity and studying its thematic structure and dynamics [Grilliches, 1990; Gokhberg, 2003]. Patenting is the most common way of protecting the results of innovative activity in most technology areas, which makes patent documentation an important source of information on new technical solutions [Gokhberg, 2003]. Patent documents contain detailed information such as the inventor and patent holder, the country and the patent office, the date of filing the application, and the actual issuing of patent. Patent data is a valuable empirical material which allows one to accomplish numerous research objectives. In particular, each such document specifies the technology groups in which the patented object belongs [Fleming, Sorenson, 2001]. In most countries including Russia, the International Patent Classification (IPC) ${ }^{2}$ is used for these purposes, whose codes, along with alternative classifications' identifiers, allow one to assess the thematic structure of patenting activity and the rate of technological development. Our distribution of patent documents by specialization area is based on the Technology Concordance Table [Schmoch, 2008] which serves as a tool for comparing the IPC with 35 technology areas including computer technology and digital communications, pharmaceuticals and biotechnologies, microstructural and nanotechnologies, and so on.

Though patent analysis procedures on the whole are standardized and well-known, measuring cities' patenting activity and technological specialization remains a very challenging task. The existing open and commercial patent databases are not sufficient for an unbiased and detailed analysis of the aforementioned territorial units.3. So, for the purposes of our study a method for working with patent documentation was

\footnotetext{
In this context relatedness is measured in terms of the International Patent Classification codes. See [Rigby, 2015] for a patent and citation analysis conducted specifically for these purposes.

Access mode: http://www1.fips.ru/wps/portal/IPC/IPC2016_extended_XML/, last accessed on: 14.06.2019.

3 The only exception is the US where residents' patent applications and patents are reflected in certain commercial databases (e.g. Orbit) which have searchby-state functionality. However, even they have serious technical drawbacks.
} 

and Steps Taken during the Process

\begin{tabular}{|c|c|}
\hline Stage & Steps Undertaken \\
\hline $\begin{array}{l}\text { Searching for, and } \\
\text { exporting all patent } \\
\text { applications for } \\
\text { inventions filed in } \\
\text { Russia by residents * }\end{array}$ & $\begin{array}{l}\text { ue to the technical limitations of the open RF Registry of Inventions }{ }^{* *} \text { (the key source of data for our analysis), } \\
\text { e objective was accomplished using the PatStat Global database which aggregates data from most of the } \\
\text { orld's patent offices including the largest ones, such as the US Patent and Trademark Office (USPTO), the } \\
\text { aropean Patent Office (EPO), and the Japan Patent Office (JPO). The period between } 2008-2016 \text { was chosen } \\
r \text { analysis } \\
\text { it* , which allowed us to assess emerging trends and avoid random short-term patenting activity } \\
\text { at a total of } 180,000 \text { patent applications were downloaded into our own PostgreSQL-based database. }\end{array}$ \\
\hline of & $\begin{array}{l}\text { porting data from relevant fields of the downloaded patent applications. After app } \\
\text { moving erroneous lines, the registry contained } 55,000 \text { units. To make the results } \\
\text { ndividuals) were excluded from the registry because of their unprecedently high pat } \\
\text { storted the picture not only for a particular city but also for the whole country. }\end{array}$ \\
\hline $\begin{array}{l}\text { es } \\
\text { of }\end{array}$ & $\begin{array}{l}\text { Imber (or a random one it there were several); then the address indicated in the documen } \\
\text { rtain limitations: firstly, it links all applications by the applicant to a single place of residen } \\
\text { ough it may have changed (e.g., in the case that the applicant moved); secondly, it automatice } \\
\text { ailing address indicated in the patent application as the applicants (as opposed to, e.g., the } \\
\text { the organization providing such services); finally, thirdly, it ignores the possibility that ap } \\
\text { ferent regions may have exactly the same name. However, the risk of error remains quite } 1 \\
\text { ta control procedures did not reveal any such cases. }\end{array}$ \\
\hline ap & $\begin{array}{l}\text { The automatic processing of postal codes indicated in the address field of the document allowed us to link } \\
\text { each patent application to a specific city. Accordingly, applications filed by applicants residing in the territories } \\
\text { now incorporated into New Moscow before } 2016 \text { were not linked to the capital city: though the administrative } \\
\text { boundaries were changed in } 2011-2012 \text {, the postal codes were updated only in } 2016 \text {. }\end{array}$ \\
\hline \multirow{3}{*}{\multicolumn{2}{|c|}{$\begin{array}{l}\text { Notes: } \\
\text { * Due to technical difficulties with obtaining relevant data, patent applications filed by Russian applicants abroad were not taken into account. However, } \\
\text { since the share of such applications over the past five years has averaged at } 14 \% \text { and their thematic structure generally matched the structure of applications } \\
\text { filed in Russia, their exclusion from the sample does not significantly affect the results of the analysis. } \\
\text { ** It was not possible to search for documents by applicant status (resident/non-resident) or divide them by technology area; restrictions on downloading, } \\
\text { etc. } \\
* * * \text { A } 10 \text {-year period was initially considered (2008-2017), but it has turned out that data for } 2017 \text { was included in the database we have been using only } \\
\text { partially (a significant time lag in updating the data is a common feature, and limitation, of all databases containing primary patent information). As a } \\
\text { result, it was decided to shorten the period by limiting it to } 2016 \text {. Among other things this allowed us to calculate indicators for equal three-year periods. } \\
\text { The practice of evaluating the averages calculated for } 2-3 \text { years is generally accepted and guarantees the objectivity of conclusions since it eliminates the } \\
\text { effect of patent activity outliers in certain years. }\end{array}$}} \\
\hline & \\
\hline & \\
\hline \multicolumn{2}{|l|}{ ource: composed by the at } \\
\hline
\end{tabular}

designed, which allowed us to overcome the existing technical limitations.

At the first (preparatory) stage we created the empirical basis for the study in line with the algorithm presented in Table 1: a registry of patent applications for inventions filed in Russia by residents and grouped by the city of their residence, technology area, and year of filing. Next, the cities were ranked by the number of domestic applications filed in 2008-2016. For high-ranking cities, the following key indicators were calculated:

- Total number of applications for inventions filed in Russia (by year)

- Average annual growth rate

- Shares of each of the 35 technology areas in the total number of applications for inventions filed by residents in the city (technology weight)

- The city's share in the total number of applications for inventions filed in Russia in each of the 35 technology areas (city weight)

- Concentration indices and, calculated as sums of weights of 5 and 10 largest technology areas, respectively, in the city's patent portfolio, which measure its specialization level (or, conversely, diversification)

- Technological specialization index (TSI) which serves as a conventional metric for accomplishing our objective ${ }^{4}$.

The TSI is calculated by comparing the structure of patent applications for inventions filed by residents in a specific city with the general structure of applications filed in Russia by residents. We have only considered the areas with a TSI value higher than 1.1 as cities' technological specialization areas, those represented in cities' patenting activity structure much better than the national average. The main results of our analysis, including descriptions of Russian technocities' technology portfolios and specialization, are presented below.

\section{Results of the Study}

Moscow and, far behind it, St. Petersburg were the expected leaders in the ranking of Russian cities by the number of patent applications filed in 2008-2016. Another nine agglomerations (Voronezh, Ufa, Kazan,

${ }^{4}$ See [Gokhberg, 2003; Khramova et al., 2013] for more about the TSI and its interpretation. 
Novosibirsk, Yekaterinburg, Krasnodar, Perm, Samara, and Tomsk) made a quite homogeneous group, significantly behind the leaders but ahead of the second ten cities. It is the leaders identified in the course of this study that we call "technocities" to emphasize the importance of their contribution to the country's technological development: technocities account for more than half of all patent applications for inventions filed by residents in Russia.

Not all technocities are among the largest Russian urban areas. For example, according to Rosstat, Voronezh, Ufa, Krasnodar, and Perm are in the second ten cities in terms of population, while Tomsk is even in $28^{\text {th }}$ place. On the other hand, Nizhny Novgorod, Chelyabinsk, Omsk, and Rostov-on-Don do belong in the ten largest cities in Russia, but they did not make it into the group of patenting activity leaders. However, the existing statistical limitations do not allow one to analyze the correlation between cities' patenting activity and their R\&D potential (in terms of expenditures, personnel, etc.). Still, the simplest comparison of the number of patented inventions with the size of the population shows that cities manage their resources differently.

On the whole, our results coincide with the conclusions of other studies in that the majority of inventions are created in large urban agglomerations, though certain small towns also have a chance to succeed [O'hUallachain, 1999]. An important factor is having a successful university or a federal-level R\&D center.

The group of leaders practically did not change over the course of ten years, indicating no patenting activity peaks in other regions and confirming the stable status-quo on the Russian IP market.

\section{"Core" Technology Cities: Specialization vs. Diversification}

In the first, theoretical section of the paper we noted that the broader the city's technological specialization area, the higher its potential for developing new technologies and for post-crisis recovery. Our analysis indicates that in these terms, two Russian technocities, Moscow and Novosibirsk, have the highest potential, due to their diversified technology portfolios (Figure 1).

In the capital, the five largest technology areas account only for about a third of all patented inventions. The highest concentration indices are noted in Perm (51.6\%), Tomsk (53.1\%), and Krasnodar (61.1\%), indicating the clear prevalence of a narrow range of technology areas in their portfolios. Furthermore,

\section{Figure 1. The Dynamics of Technocities' Concentration Index $\left(\mathrm{C}_{5}\right)$}

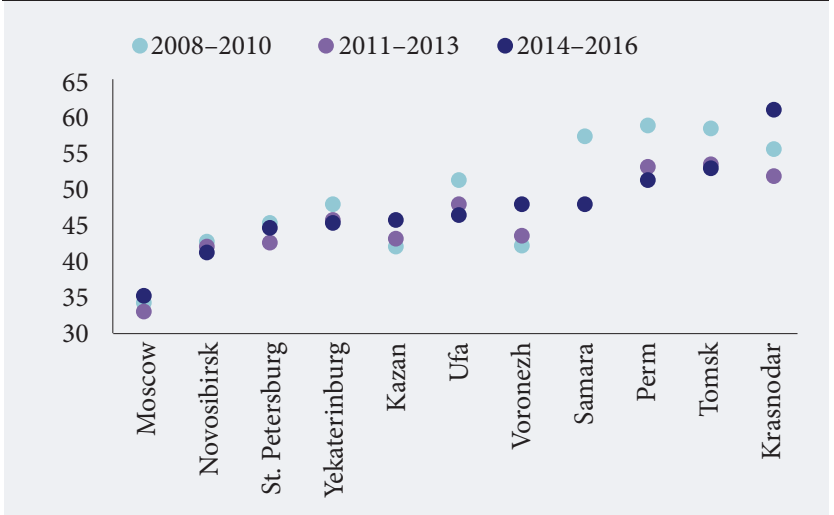

Source: composed by the authors.

Krasnodar's index significantly increased in 2008-2016, contrary to the diversification trend that is common for Russian technocities.

\section{Technocities' Technological Specialization Areas}

The main results are presented in Table 2. Technocities' technological specialization areas are marked in red. Reading the table horizontally, you can see the cities with potential to develop certain technologies. Reading the table by column, you can get an idea of the cities' technological portfolios and the areas of their current specialization.

Our analysis allows us to break technocities down into three groups, on the basis of the characteristics of the technology areas they specialize in ${ }^{5}$. The first group comprises cities primarily focused on innovative technology areas, with high technologies dominating their portfolios. We included Moscow, St. Petersburg, and Tomsk in this group.

Moscow's technological specialization includes several information and communication technology areas. The metropolitan region is a key developer of new information technologies, home to domestic IT companies actively patenting their inventions in Russia and abroad, such as Kaspersky Lab, Yandex, and ABBYY. In the computer technology field, Moscow accounts for about half of all patent applications filed by residents in Russia in 2014-2016. Other high-tech specialization areas in Moscow include biotechnology and micro-

\footnotetext{
4 The International Patent Classification (IPC) and OKVED provided the methodological basis for the suggested typology of technocities [Van Looy et al., 2014] along with the classification of economic activities [Galindo-Rueda, Verger, 2016].
} 
Table 2. Technocities' Technological Specialization Areas: 2014-2016

\begin{tabular}{|c|c|c|c|c|c|c|c|c|c|c|c|c|}
\hline & & 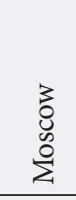 & 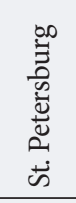 & 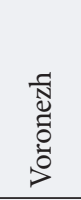 & 苛 & 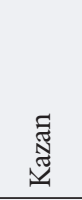 & 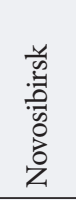 & 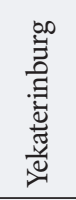 & 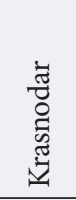 & $\Xi_{\tilde{D}}$ & 节 & है \\
\hline \multicolumn{13}{|c|}{ Electrical engineering } \\
\hline 1 & $\begin{array}{l}\text { Electrical equipment, equipment for the } \\
\text { generation, transmission, and distribution } \\
\text { of electricity }\end{array}$ & * & * & & * & & 1.50 & 1.63 & * & & 1.14 & 2.27 \\
\hline 2 & Audio-visual technologies & 1.15 & 1.45 & & & & & 1.30 & & & & \\
\hline 3 & Telecommunication & & 1.67 & 2.37 & & & & & & & & 1.98 \\
\hline 4 & Digital communication & 1.16 & 3.42 & & & & & & & & 1.21 & \\
\hline 5 & Basic communication systems & & 1.30 & 3.86 & & & & & & & & \\
\hline 6 & Computer technologies & 1.85 & 1.52 & & & & & & & & & \\
\hline 7 & Management information technologies & 1.73 & 1.16 & & & 2.71 & & 1.85 & & & 1.15 & \\
\hline 8 & Semiconductors & 1.44 & 1.22 & 1.23 & & & 1.67 & & & & & 1.55 \\
\hline \multicolumn{13}{|c|}{ Instruments } \\
\hline 9 & Optics & & 1.63 & & & 2.59 & 4.09 & & & & & \\
\hline 10 & Measurement technologies & * & 1.77 & * & * & * & 1.43 & * & * & * & * & 1.73 \\
\hline 11 & Biomaterial analysis & & & & & & & 1.19 & & 2.66 & 1.27 & 2.33 \\
\hline 12 & Instrumentation & & 1.33 & & & 1.27 & & & & & 1.12 & \\
\hline 13 & Medical technologies & 1.12 & 1.31 & * & 1.10 & 1.11 & * & 1.26 & * & * & 1.78 & 1.60 \\
\hline \multicolumn{13}{|c|}{ Chemical engineering } \\
\hline 14 & Fine and organic chemistry & & & & 6.44 & 1.32 & 1.96 & 1.14 & 1.35 & 2.35 & & 1.24 \\
\hline 15 & Biotechnology & 1.87 & & & & & 2.18 & & & & & \\
\hline 16 & Pharmaceuticals & 1.10 & * & & 1.94 & 1.11 & 1.25 & * & * & * & * & 1.71 \\
\hline 17 & Macromolecular chemistry, polymers & 1.11 & & 1.18 & 1.32 & 2.02 & & & & & & 1.43 \\
\hline 18 & Food chemistry & * & & 4.01 & & & & * & 6.21 & & & \\
\hline 19 & Basic materials chemistry & * & & & 3.04 & 2.92 & & & 1.72 & 1.41 & & 1.13 \\
\hline 20 & Materials, metallurgy & * & * & & & * & * & 2.66 & & 1.58 & 1.43 & 1.67 \\
\hline 21 & Surface treatment, coating & & & 1.14 & 1.53 & 1.28 & 1.14 & 1.39 & & 1.22 & & \\
\hline 22 & Microstructural and nanotechnologies & 1.16 & & & & & 2.01 & 1.69 & & 1.32 & & 1.57 \\
\hline 23 & Chemical engineering & * & * & * & 1.87 & * & 1.96 & * & 1.95 & & & 1.15 \\
\hline 24 & Environmental protection technologies & & & & 1.96 & & & & & & & \\
\hline \multicolumn{13}{|c|}{ Mechanical engineering } \\
\hline 25 & Processing & & 1.52 & 1.46 & & & & 1.65 & & 1.26 & & \\
\hline 26 & Machine tools & & & & & & & 1.13 & & & 1.34 & \\
\hline 27 & Engines, pumps and turbines & * & * & 1.33 & * & 1.80 & & * & & 2.27 & 2.07 & \\
\hline 28 & Paper and textile machines & & 1.37 & & & 1.26 & & & & 1.47 & & \\
\hline 29 & Other special-purpose machinery & * & * & 1.47 & & * & * & & 2.07 & * & * & \\
\hline 30 & Thermal processes and heating devices & & & 2.02 & 1.29 & & 1.97 & 1.16 & & & & \\
\hline 31 & Mechanical components & * & & & * & * & & & & & 1.26 & \\
\hline 32 & Transport & * & 1.45 & & & * & & * & & & 1.14 & \\
\hline \multicolumn{13}{|c|}{ Others } \\
\hline 33 & Furniture, games & & & 2.30 & & & & 3.33 & & 1.78 & 1.13 & \\
\hline 34 & Other consumer products & 1.65 & & & & & & & 1.42 & & & \\
\hline 35 & Civil construction & * & * & * & 1.13 & 1.42 & * & * & & 2.67 & 1.16 & * \\
\hline
\end{tabular}


structural and nanotechnologies. In the first case, the city accounts for almost $50 \%$ of all patent applications and in the second for about a third of them. Over the past decade, areas such as semiconductors, materials chemistry, surface treatment, and coating technologies have also been actively developing in the capital city. On the whole, the technocity of Moscow's technology portfolio is highly diversified and includes impressive groundwork results in many industries, which increases the likelihood of new technologies' emergence.

St. Petersburg specializes in developing electrical engineering technologies almost across their entire range, including audio-visual, telecommunication, and computer technology. In terms of quantitative indicators, the best results so far have been achieved in digital communication (26\% of all patent applications filed by residents in Russia in 2014-2016). The city's technological specialization also traditionally includes optics, instrumentation, medical technologies, and biotechnology.

Tomsk displays an appreciable lead in measurement technologies (the largest area in the city's patent portfolio), fine and organic chemistry, pharmaceuticals, microstructural and nanotechnologies. Notably, none of the technologies in the last two classification groups (Mechanical engineering and Other) is present.

The second group of technocities comprises cities mostly focused on developing less research-intensive, or low technologies: Krasnodar and Perm.

Krasnodar specializes in a range of chemical areas such as food chemistry, materials chemistry, chemical engineering, and fine and organic chemistry. In some of them, the city displays very impressive performance. For example, Krasnodar accounts for over 13\% of food chemistry-related patent applications filed by residents in Russia in 2014-2016. More than a quarter of all inventions patented by applicants from this city belong in this field. The "Other special-purpose machinery" group also has a strong position in the city's portfolio (it mainly comprises agricultural machinery).

Perm's technological specialization includes a number of areas related to chemical and mechanical engineering including engines, pumps, turbines, materials, metallurgy, machinery for making paper and textiles, and basic materials chemistry. In the first one, applicants from Perm filed almost $4 \%$ of all Russian patent applications for inventions in 2014-2016 - a significant contribution, given that the city's average share in all technology areas does not exceed $1.5 \%$. Certain areas traditionally included in the high-technology group are also being developed in Perm, such as fine and organic chemistry, microstructural and nanotechnologies. Nanotechnology only recently became part of the city's technological specialization (in 2014-2016). Previously there was either no patenting activity in this area at all (in 2008-2010), or it was insignificant (in 2011-2013). Perm can be considered a borderline case: the more traditional areas which obviously dominate the current technological specialization structure with time may be replaced by a number of new areas whose high growth rate could "shake up" the existing model.

Finally, the third and most numerous group comprises technocities specializing in a whole range of areas, regardless of their technological level or research intensity. We included Voronezh, Ufa, Kazan, Novosibirsk, Yekaterinburg, and Samara in this group.

Voronezh specializes in developing a wide range of technologies from digital communications to specialpurpose machinery. The mix of technology areas where the city's contribution to Russian applicants' patenting activity is most apparent also highlights the diversified nature of its technological development. Food chemistry is the leader here (Voronezh's share is $11.5 \%$, while the city's average in all areas is $3.1 \%$ ), along with basic communication processes (11.0\%). Several high technology areas fell out of the city's technological specialization during the period under consideration, among them audio-visual and digital communication technologies.

Ufa is clearly focused on developing chemical technologies: they account for half of all patent applications filed by applicants from this city in Russia, with numerous relevant areas falling within the scope of its specialization. Ufa makes a special contribution to the development of fine and organic chemistry on the national scale: more than $14 \%$ of patent applications (while the city's overall share is just about 2.5\%). This is mainly due to the activities of a key developer in this field, the Institute of Petrochemistry and Catalysis of the RAS.

Kazan's specialization includes the development of new semiconductors and polymers, fine and organic chemical technologies, and basic materials chemistry. Optics has a special position in the technological portfolio of Novosibirsk: about $9 \%$ of domestic inventions in this field in 2014-2016 were made in this city. Novosibirsk's potential in biotechnology is also noteworthy: in technocities' ranking by the number of patent applications filed in Russia in this field during the past decade, the city has invariably remained third (after Moscow and St. Petersburg). The credit largely goes to the Institute of Chemical Biology and Fundamental Medicine of the SB RAS, the city's most active applicant in this area. The calculated concentration indices indicate a gradual diversification of Yekaterinburg's and Samara's technological portfolios over the last decade. As a result, to- 
day both these technocities specialize in developing a whole range of new areas, high- and low-tech alike. The first segment comprises management IT, biomaterial analysis, medical technologies for Yekaterinburg, plus audio-visual, microstructural and nanotechnologies, while the second comprises materials, metallurgy, furniture, and games.

\section{Conclusion}

Large cities act as drivers of technological development in Russia and most countries of the world. Due to the geographical concentration and access to resources (financial, human, and technical), new technologies are developed most proficiently there, which among other things is expressed in patenting activity. Over the last decade the group of technology leaders in the country remained virtually unchanged. Such stability on the one hand may indicate that other players on the domestic technology market made no significant breakthroughs, but on the other confirm the high potential and sustainability of leading agglomerations. The latter's strategies and competencies are highly diversified, which is quite predictable given the differences in their location, access to natural resources, well-being, and the presence of major R\&D and educational centers. The practical importance of our study is not only in providing an empirical confirmation of this intuitively reliable hypothesis, but also in a comprehensive assessment of the patent portfolios and technological specializations of Russian technocities, which may help governments make decisions and promote technological development at the regional and even municipal levels.
The study also allowed us to identify the areas all Russian technocities are involved in, which thus can be considered as a reliable basis for the further development of the country's technological potential. In particular, such a field is measurement technologies (St. Petersburg, Novosibirsk, and Tomsk specialize in them, but all technocities are actively involved as well: in almost all of them this is one the largest areas in terms of the number of patent applications). Thanks to the innovative productivity of developers from various regions, Russia currently is the $8^{\text {th }}$ in the world in terms of patenting activity in the measurement technologies area, while in the overall patenting ranking it holds $11^{\text {th }}$ place ${ }^{6}$. A similar situation is observed in medical technologies, civil engineering, and, in recent years, in pharmaceuticals.

Despite the limitations of the study mentioned in the introductory part of the paper, it paves the way for further analysis of cities' technological development, offering a methodology for processing patent data at the level of specific administrative territorial units. In this regard, a comprehensive study of particular technologies' development in major cities appears to be a promising research area. Further research will contribute not only to identifying technocities' sustainable competencies, but also discovering emerging trends and weak signals which can affect cities' future technological development paths.

The paper was written in the scope of research on the topic "Approaches to building statistical indicators of current state and dynamics of scientific and technological development" conducted by the HSE in 2019.

\section{References}

Gokhberg L. (2003) Statistika nauki [Statistics of Science], Moscow: TEIS.

Rospatent (2018) Ezhegodnyi otchet o deyatelnosti [Annual Report 2017], Moscow: Rospatent (in Russian).

Andersson R., Quigley J.M., Wilhelmsson M. (2005) Agglomeration and the special distribution of creativity. Regional Science, vol. 84, no 3, pp. 445-464.

Archibugi D., Pianta M. (1992) Specialization and size of technological activities in industrial countries: The analysis of patent data. Research Policy, vol. 21, no 1, pp. 79-93.

Balland P.-A., Boschma R., Frenken K. (2015a) Proximity and Innovation: From Statics to Dynamics. Regional Studies, vol. 49, no 6, pp. 907-920.

Balland P.-A., Rigby D., Boschma R. (2015b) The technological resilience of US cities. Cambridge Journal of Regions, Economy and Society, vol. 9, pp. 167-184.

Boschma R. (2015) Towards an Evolutionary Perspective on Regional Resilience. Regional Studies, vol. 49, no 5, pp. 733-751.

Boschma R., Balland P.-A., Kogler D.F. (2014) Relatedness and technological change in cities: The rise and fall of technological knowledge in US metropolitan areas from 1981 to 2010. Industrial and Corporate Change, vol. 24, no 1, pp. 223-250.

Cantwell J., Vertova G. (2004) Historical evolution of technological diversification. Research Policy, vol. 33, pp. 511-529.

\footnotetext{
${ }^{6}$ The authors' calculations based on the WIPO data for 2017 (see WIPO IP Statistics Data Center, access mode: https://www3.wipo.int/ipstats/index. htm?tab=patent, last accessed on: 20.11.2018).
} 
Carlino G., Kerr W. (2014) Agglomeration and Innovation (Working Paper 15-007), Boston, MA: Harvard Business School. Available at: http:// real.wharton.upenn.edu/ duranton/Duranton_Papers/Handbook/Agglomeration_and_innovation.pdf, accessed15.11.2018.

Cortright J., Mayer H. (2001) High Tech Specialization: A Comparison of High Technology Centers. Washington, D.C.: The Brookings Institution, Center on Urban and Metropolitan Policy. Available at: https://www.brookings.edu/wp-content/uploads/2016/06/specialization.pdf, accessed15.11.2018.

Dachs B., Mahlich J., Zahradnik G. (2007) The Technological Competencies of Korea's Firms: A Patent Analysis. Innovation and Technology in Korea: Challenges of a Newly Advanced Economy (eds. J. Mahlich, W. Pascha), Heidelberg, NY: Physica-Verlag, pp. $127-146$.

Ejermo O. (2005) Technological diversity and Jacob’s externality hypothesis revisited. Growth and Change, vol. 36, no 2, pp. 167-195.

Fleming L., Sorenson O. (2001) Technology as a complex adaptive system: Evidence from patent data. Research Policy, vol. 30, pp. 117-132.

Galindo-Rueda F., Verger F. (2016) OECD Taxonomy of Economic Activities Based on RઐD Intensity (OECD Science, Technology and Industry Working Paper 2016/04), Paris: OECD.

Giannitsis T., Kager M. (2009) Technology and Specialization: Dilemmas, Options, Risks?, Brussels: European Commission.

Glaeser E., Kallal H., Scheinkman J., Shleifer A. (1992) Growth in Cities. The Journal of Political Economy, vol. 100, no 6, pp. $1126-1152$.

Grilliches Z. (1990) Patent statistics as economic indicators: A survey. Journal of Economic Literature, vol. 28, pp. $1661-1707$.

Ha S.H., Liu W., Cho H., Kim S.H. (2015) Technological advances in the fuel cell vehicle: Patent portfolio management. Technological Forecasting and Social Change, vol. 100, pp. 277-289.

Jacobs J. (1969) The Economy of Cities, New York: Random House.

Jacobs J. (1984) Cities and the Wealth of Nations: Principles of Economic Life, New York: Random House.

Jaffe A., Trajtenberg M., Henderson R. (1993) Geographical localization of knowledge spillovers as evidenced by patent citations. The Quarterly Journal of Economics, vol. 108, no 3, pp. 577-598.

Khramova E., Meissner D., Sagieva G. (2013) Statistical patent analysis indicators as a means of determining country technological specialization (HSE Working Paper. Series: Science, Technology and Innovation, WP BRP 09/STI/2013), Moscow: HSE. Available at: https://www.hse. ru/data/2013/04/10/1297571825/09STI2013.pdf, accessed10.11.2018.

Kogler D.F., Heimeriks G., Leydesdorff L. (2018) Patent portfolio analysis of cities: Statistics and maps of technological inventiveness. European Planning Studies, vol. 26, no 11, pp. 2256-2278.

Kogler D.F., Rigby D., Tucker I. (2013) Mapping Knowledge Space and Technological Relatedness in US Cities. European Planning Studies, vol. 21, no 9, pp. 1374-1391.

O’hUallachain B. (1999) Patent places: Size matters. Journal of Regional Science, vol. 39, no 4, pp. 613-636.

Patel P., Pavitt K. (1997) The technological competencies in the world's largest firms: Complex and path dependent, but not too much variety. Research Policy, vol. 26, pp. 141-156.

Pianta M., Meliciani V. (1996) Technological specialization and economic performance in OECD countries. Technology Analysis \& Strategic Management, vol. 8, no 2, pp. 157-174.

Rigby D. (2015) Technological relatedness and knowledge space: Entry and exit of US cities from patent classes. Regional Studies, vol. 29, no 11, pp. 1922-1937.

Schmoch U. (2008) Concept of a technology classification for country comparisons. Final Report to the World Intellectual Property Organization (WIPO), Karlsruhe: Fraunhofer Institute for Systems and Innovation Research.

Strumsky D., Lobo J., van der Leeuw S. (2012) Using patent technology codes to study technological change. Economics of Innovation and New Technology, vol. 21, no 3, pp. 267-286.

van Looy B., Vereyen C., Schmoch U. (2014) Patent Statistics: Concordance IPC V8 P. NACE Rev.2, Paris: Eurostat.

Vlckova J., Kasprikova N., Vlckova M. (2018) Technological relatedness, knowledge space and smart specialization: The case of Germany. Moravian Geographical Reports, vol. 26, no 2, pp. 95-108.

Xia L., Hu J.-Y. (2014) Analysis of the relationship between specialization and innovation of technology in Chinese cities. Applied Mechanics and Materials, vol. 522-524, pp. 1577-1580. 